\title{
Innovative Strategies for the European SMEs: AiRT Project Main Remarks
}

\author{
Virginia Santamarina-Campos and Stephan Kröner
}

\begin{abstract}
The aim of this chapter is to summarise the main achievements of AiRT project, that have been presented in this book, and to provide thought-provoking impulses on the bases of our experiences as well to the IT companies as to CIs to "think outside of the box". By doing so, we demonstrated that both the areas of IT innovation and creative companies can benefit mutually. In fact, we are of the opinion that big part of "real" innovation can only be achieved by transferring knowledge between different sectors and adapting the corresponding technology or approaches to the needs of the demanding sectors. This requires inevitable inter- $/$ or transdisciplinary teams that arise out of given circumstances, which might be composed of just a few experts from different sectors working together on a common goal.
\end{abstract}

\section{Introduction}

The use of Design Thinking allowed us to generate a disruptive innovation. Being able to experiment, as a tool that in origin was born as something residual, focused on creative industries, it has been able to transform an innovative product for new industries (Christensen 2011). This methodology has provided a change of mentality in the interdisciplinary team, having a great positive impact on both the consortium and its results and approach to exploitation.

This is how the AiRT project was born, when a real need by a certain part of the creative industry was detected, which could only be solved by an interdisciplinary team with innovative approaches. With this book, written together with the whole consortium involved, we are happy that we could share our problem-solving

\footnotetext{
V. Santamarina-Campos $(\bowtie)$

Conserv. \& Restoration of Cult. Heritage Department, Universitat Politècnica de València, Valencia, Spain

e-mail: virsanca@upv.es

\section{S. Kröner}

Universitat Politècnica de València, Valencia, Spain
} 
approach and findings with others, be it research centres/universities or companies in general (and SMEs in particular).

\section{Conclusions}

The creative and cultural industries (CCIs) have shown exceptional resilience to the economic crisis and are well-placed to grow further in the future due to their role as forerunners in digital innovation (EY 2014).

Although the typical companies of the creative industry are usually small businesses (with few employees), their economic impact should not be undervalued. The creative and cultural industries contribute more than 4\% of the GDP of the EU, with 535.9 billion euros in turnover and employ more than 7 million people (EY 2014). This value is often underrated by the general public, or rather unknown, and therefore the economic impact on the market is also often underestimated (apart from the cultural value added). Rafa Boix and Pau Rausell illustrated this very comprehensively with the hard data provided in chapter "The economic impact on the creative industry in the European Union".

From the perspective of an economist, the launch of a new product (NPD), can only be successful when there is a real need in the society, or at least if a need can be generated by this new development. The following chapter of the book thus addressed exactly this topic: the need(s) of the creative industries. The authors, Blanca de-Miguel-Molina and Marival Segarra-Oña, very concisely described the needs of the creative industries and how the market for their services is increasing. They clearly identified the targeted markets, the potential of those and the obstacles to overcome. When it comes to the creative industry sector one should be aware of some important facts:

- with over 900,000 companies in Europe the targeting size is big

- it is what economists call an atomised market

- firms are typically composed of about five employees (small sized)

This leads to typical drawbacks concerning innovation processes (lack of resources), but at the same time the SME character of the firms can be converted as an advantage. The company's structures are more flexible, and innovation processes can be applied much faster compared to global players. The AiRT project takes all these considerations into account. We detected a need by the CIs to use creative filming tools such as drones (RPAS) not only outdoors, but also for indoor footage. By doing so, we demonstrated that CI can enhance their services in order to improve their market position. Moreover, the limited resources (available investment amount) are also taken into account, since AiRT will be released at an affordable price, which will be an important characteristic of our value proposition.

By exposing other cases of the use of innovative tools and technology, the possible impact of innovative products on the services offered in the CI field has been demonstrated (see chapter "Succesful cases of the use of innovative tools and technology in the creative industries field"). Technology transfer has had, so far and 
will have in the future, a strong impact on the film industry as a whole. Digital recording, motion graphics and post-production process can be cited just as a few more examples to illustrate the IT implication which took place in this sector.

It must be highlighted again, that AiRT project's methodology is based on Design Thinking (Both 2009), where the participation of the CIs is present throughout the process. Five main phases were established, whereas the first one detected the needs through the participation of the targeted sectors via focus groups in UK, Belgium and Spain. In the second phase, the information has been synthesised and processed, and subsequently storytelling approach applied, which has been developed in detail in chapter "Storyboarding as a means of requirements elicitation and user interface design: an application to the drone's industry" by Abad et al. It has been shown that this technique is very useful in order to verify whether all the demanded features by CIs can be integrated (or have been integrated already). This was a very important step to assure that the final outcome, the graphical user interface (GUI), meets the required user-friendly interface.

The fourth phase of AiRT methodology can be, from an engineering point of view, described as the most critical/difficult phase of AiRT project: the integration process. Here in this book, first of all, we described in detail the Indoor Positioning System (IPS) in chapter "How a cutting-edge technology can benefit the creative industries: the positioning system at work" (Vermeiren et al.) and the challenges for the integration in a RPAS. The following chapter was been dedicated to presenting the final result after the successful integration process: the indoor drone with advanced features. Why did AiRT project opt for this state of the art (SOA) technique for indoor localisation, based on UWB? As shown in detail in the chapter above, the IPS developed by Pozyx is an affordable solution and is thus accessible for even small sized companies. This has been, since the beginning of the project, an essential requirement. It must be noted and emphasised again, that currently, the most precise IPS solution available is based on motion capture technologies with costs exceeding 200,000 $€^{1}$ (VICON n.d.) (just a positioning system), whereas the whole AiRT solution (drone with IPS etc.) is expected not to exceed 10,000 €. Thanks to the implementation of the four-antenna approach and new algorithms, we demonstrated that UWB-based indoor positioning systems are suitable for drone integration and provide sufficient precision to allow professional high-quality filming. Furthermore, again, special emphasis was lain on a user friendly, selfexplaining deployment of the system.

What makes our drone different from others? Basically, it can be stated that, up until now, the AiRT solution could be considered as unique when it comes to professional indoor filming by creative industries. Since, in the AiRT consortium, the Creative Filmmaking Agency, and thus a targeted end-user, Clearhead is

\footnotetext{
${ }^{1}$ Estimated price. Keep in mind those systems are normally designed for relatively small-sized rooms $(6 \mathrm{~m} \times 6 \mathrm{~m} \times 3 \mathrm{~m}$; width/length/height). Larger rooms require more motion capture cameras (prices for each camera are around $2445 €)$. In typical AiRT use environments $(20 \mathrm{~m} \times 20 \mathrm{~m} \times$ $10 \mathrm{~m}$ ) more than 100 motion capture cameras might be needed.
} 
involved, the most demanded features for professional footage has been integrated. In addition, the continuous involvement of the creative industries and ICT experts of the MCI ensured success of both need analysis and feasibility of the required features. In particular, the ability to programme flight paths, mark key frames, change (almost) any parameter of the filming camera make up the difference to competitors.

Also, a unique approach-introducing a number of flight modes-provides the AiRT drone with a very sophisticated safety system. The flight modes provide users with different degrees of freedom, from a totally manual flight option to a totally autonomous flight, and a number of intermediate flight modes with configurable restrictions (such as flight at a given altitude or keep a distance to the object in front). This adaptability to different filming environments or drone flying skills by the operator ensures a safe flight at any time.

Although AiRT emphasised the usability of the system in each step, we dedicated the last chapter to the relationship of the industry with the public administration, in particular the co-regulation for training. This is because in the different European countries, co-regulation is used to provide practical training to drone pilots, which is a key factor for the industry. We hope, that we could clarify the process of how to become a drone operator and a pilot and how the industry is involved in this task.

\section{Final Remarks}

Financing tech-transfer and innovation, as demonstrated in chapter "Financing techtransfer and innovation: an application to the creative industries" by Cruz et al., especially for small (and medium) sized companies, is an important tool introduced by the European Commission. In particular, Horizon 2020, launched in 2014, is addressed to the topics of research and development. Innovation under such programmes should be tailored to the needs of the end-users (market proximity), proven by demonstration and piloting. While an increase of project funding that involved creative industries was recognisable already in the 7th European Framework Programme (FP7; 2007-2013), an exponential increase of funded projects with CI implication can be observed under H2020.

These funding programmes are particularly important in the area of the creative industry sector, as innovative ideas often exist, but realisation fails due to a lack of resources. This is also true in the case of the AiRT project, where three small SME companies and a university have joined forces to work on a common idea and put it into reality. Without the financial support of the Horizon 2020 programme, the AiRT system would not have been possible. This is why we want to especially acknowledge the funding received from the European Union's Horizon 2020 research and innovation programme under Grant Agreement No 732433. 


\section{References}

Both T (2009) Bootcamp Bootleg. https://dschool.stanford.edu/resources/the-bootcamp-bootleg Christensen CM (2011) The innovator's dilemma: the revolutionary book that will change the way you do business. Am Polit Sci Rev 94. Harper Collins, New York

EY (2014) Creating growth: measuring cultural and creative markets in the EU. EYGM Limited, France. http://www.ey.com/Publication/vwLUAssets/Measuring_cultural_and_creative_markets_ in_the_EU/\$FILE/Creating-Growth.pdf. Accessed 16 Mar 2018

VICON (n.d.) VICON installation. https://www.vicon.com/installation. Accessed 8 Mar 2018

Open Access This chapter is licensed under the terms of the Creative Commons Attribution 4.0 International License (http://creativecommons.org/licenses/by/4.0/), which permits use, sharing, adaptation, distribution and reproduction in any medium or format, as long as you give appropriate credit to the original author(s) and the source, provide a link to the Creative Commons license and indicate if changes were made.

The images or other third party material in this chapter are included in the chapter's Creative Commons license, unless indicated otherwise in a credit line to the material. If material is not included in the chapter's Creative Commons license and your intended use is not permitted by statutory regulation or exceeds the permitted use, you will need to obtain permission directly from the copyright holder. 